\title{
Editorial
}

\section{O papel dos Eventos em Ensino de Ciências e a Formação de Professores}

\author{
Marcelo Pimentel da \\ Silveira \\ martzelops@gmail.com \\ Universidade Estadual de Maringá \\ (UEM), Maringá, Paraná, Brasil \\ Neide Maria Michellan \\ Kiouranis \\ nmmkiouranis@gmail.com \\ Universidade Estadual de Maringá \\ (UEM), Maringá, Paraná, Brasil
}

Página | 1
Desde 1995, artigos voltados para a pesquisa em Ensino de Química publicados, por exemplo, nas revistas Química Nova e Química Nova na Escola, revelam que a realização de eventos regionais e nacionais, como resultados dos trabalhos de ensino e de pesquisa realizados por professores, pesquisadores e estudantes de graduação e pós-graduação, se apresentam como um marco importante para consolidação da área de pesquisa em Ensino de Química no país.

Nesse contexto, se destacam o Encontro de Debates em Ensino de Química realizado desde 1980 no estado do Rio Grande do Sul e, em 1982, o I Encontro Nacional de Ensino de Química realizado na Unicamp. Desde então, os encontros citados contribuíram para promover a divulgação das pesquisas em Ensino de Química, realizar debates a respeito de questões relevantes, bem como de problemas enfrentados na escola, estratégias de ensino, áreas de interesse e o desenvolvimento de linhas específicas de pesquisas, além de possibilitar encontros entre pesquisadores renomados e emergentes, assim como estudantes de graduação e pós-graduação e professores de Química da Educação Básica.

A promoção de eventos se estendeu para várias regiões do país, tais como o Encontro de Educação em Química na Bahia (EDUQUI), Encontro Centro-Oeste de Debates sobre Ensino de Química e Ciências (ECODEQ), Congresso Paranaense de Educação em Química (CPEQUI) e o Encontro Paulista de Pesquisa em Ensino de Química (EPPEQ) em consonância com o crescimento do número de pesquisadores em Educação Química, com a expressiva criação de Programas de Pós-Graduação em Ensino das Ciências, principalmente, a partir do início do século XXI.

Mas, não apenas a pesquisa tem se destacado no âmbito dos eventos, ressalta-se o importante papel da comunidade de educadores e pesquisadores em Ensino de Química no contexto das mudanças que o país tem passado, desde o final da década de 1980, no cenário político, social e educacional como, por exemplo: a aprovação da Constituição da República Federativa do Brasil de 1988; a Lei de Diretrizes e Base da Educação Nacional (LDB) - Lei 9.394 de 20 de dezembro de 1996; os Parâmetros Curriculares Nacionais para o Ensino Fundamental (1997) e Médio (1998) e, recentemente, a Reforma do Ensino Médio; A Base Nacional Comum Curricular (BNCC) e a reforma dos cursos de licenciatura de acordo com as Diretrizes Curriculares Nacionais para a Formação Inicial e Continuada dos Profissionais do Magistério da Educação Básica - Resolução 02/2015 - CNE.

No estado do Paraná, a trajetória da Educação em Química até sua consolidação, não tem sido diferente, destaca-se o significativo aumento de pesquisadores e Programas de Pós-Graduação em Educação para a Ciência e/ou Ensino de Química, 
notadamente, a contribuição do Congresso Paranaense de Educação Química (CPEQUI), um evento bianual, organizado pelas Instituições Paranaenses de Ensino Superior que mantêm cursos de Licenciatura em Química e tem por objetivo congregar professores, pesquisadores e estudantes da área para socializar e discutir ideias, produções, concepções e práticas.

Iniciado em 2009, o I Congresso Paranaense de Educação Química, foi realizado na cidade de Londrina, por meio de uma parceria estabelecida entre a Universidade Estadual de Londrina e a Universidade Estadual do Oeste do Paraná, teve como tema "A Educação Química no Paraná".

O II Congresso Paranaense de Educação Química foi realizado em 2011, pela UNIOESTE, em parceria com a UEL, na cidade de Toledo, sob o tema "No ano internacional da Química, os desafios de educar para um mundo melhor".

O III Congresso Paranaense de Educação Química, foi organizado pela Universidade Estadual de Ponta Grossa, em 2013, e teve como tema "A Educação Química na Universidade e na Escola: Encontros e Desencontros".

O IV Congresso Paranaense de Educação Química foi realizado em 2015, na cidade de Curitiba, pela Universidade Federal do Paraná, com a temática "A Pesquisa em Educação em Química no Paraná".

A $V$ edição do evento, pela Universidade Estadual de Maringá, deu visibilidade à "Educação Química e políticas educacionais: impactos no ensino, na pesquisa e na formação de professores", trazendo para o debate o atual e conturbado contexto social, político, econômico, cultura e educacional do país.

No cenário apontado, a Revista ACTIO: Docência em Ciências vinculada à Universidade Tecnológica do Paraná (UTFPR), desde sua criação, registra também com suas publicações, a evolução da comunidade de investigadores e destaca a pesquisa para a formação de professores, na perspectiva da práxis voltada para a constituição do ser professor pesquisador. Assim sendo, discutem-se as contribuições das pesquisas que enfocam os pressupostos desses campos de saberes, no que tange ao fortalecimento dos Grupos de Pesquisa em Educação em Ciências no Estado do Paraná.

Nesta edição, a revista reúne trabalhos selecionados do V Congresso Paranaense em Educação Química, submetidos ao processo e avaliação, com base em critérios estabelecidos pelo seu editor, no sentido de garantir o nível de exigência para efeito de publicação, buscando também compatibilizar o conteúdo do texto à experiência do revisor, com o objetivo de divulgar as pesquisas desenvolvidas no âmbito das universidades paranaenses e de outros estados.

Finalizamos este editorial reiterando nossos agradecimentos. 
Recebido: 19 dez. 2016

Aprovado: 19 dez. 2016

DOI: $10.3895 /$ actio.v2n1.7100

Como citar: SILVEIRA, M. P. da; KIOURANIS, N. M. M. O papel dos Eventos em Ensino de Ciências e a

Formação de Professores. ACTIO, Curitiba, v. 2, n. 1, p. 1-3, jan./jul. 2017. Disponível em:

$<$ https://periodicos.utfpr.edu.br/actio>. Acesso em: XXX.

\section{Correspondência:}

Marcelo Pimentel da Silveira

Av. Colombo, 5790 Bloco 21 - Sala 13 - Jardim Universitário, CEP.: 87020-900 Maringá, Paraná, Brasil

Direito autoral: Este artigo está licenciado sob os termos da Licença Creative Commons-Atribuição 4.0

Internacional.

\section{(c) (1)}

